\title{
The effects of barnidipine on an experimental ischemia reperfusion model of spinal cord injury and comparison with methyl prednisolone
}

\author{
(D) Iskender Samet Daltaban, ${ }^{1}$ (D) Sema Misir, ${ }^{2}$ (D) Vugar Ali Turksoy, ${ }^{3}$ (D) Hakan Ak, ${ }^{1}$ (D) Ertugrul Cakir ${ }^{4}$ \\ ${ }^{1}$ Department of Neurosurgery, Bozok University Faculty of Medicine, Yozgat, Turkey \\ 2Department of Biochemistry, Cumhuriyet University Faculty of Pharmacy, Sivas, Turkey \\ ${ }^{3}$ Department of Public Health, Bozok University Faculty of Medicine, Yozgat, Turkey \\ ${ }^{4}$ Department of Neurosurgery, Karadeniz Technical University, Faculty of Medicine, Trabzon, Turkey
}

\begin{abstract}
OBJECTIVE: Increased intracellular calcium concentration plays an important role in the secondary mechanism of spinal cord injury. In the presenting experimental study, we aimed to evaluate the healing effect of barnidipine, which has a high affinity for L-type calcium channels, on acute spinal cord injury and to compare its effects with those of methylprednisolone.

METHODS: A total of 32 Spraque Dawley albino adult female rats were divided into 4 groups; group 1: sham-operated $(n=8)$, group 2: only ischemia $(n=6)$, group 3: barnidipine-treated $(n=8)$, and group 4: methylprednisolone-treated $(n=6)$. An ischemia-reperfusion model was created by clipping the abdominal aorta in the rats. Motor examination was performed 1 hour after the surgical procedure and before sacrification. Immediately following the second motor examination, rats were sacrificed and tissue samples were taken for histopathological examination and for testing of tissue malondialdehyde (MDA) levels. RESULTS: A significant correlation of motor examination was found between the sham-operated and barnidipine-treated groups and the sham-operated and only ischemia groups at the $1^{\text {st }}$ and $24^{\text {th }}$ hour $(p<0.008)$. There was no significant difference between the only ischemia and barnidipine-treated groups and only ischemia and methylprednisolone-treated groups ( $p>0.008)$. Light microscopic examination of the sham-operated group revealed findings consistent with normal spinal cord structure. In group 2, 3, and 4, light microscopic examination revealed polymorphonuclear leukocyte infiltration and a small amount of axonal swelling. There was no significant correlation between the ischemia and barnidipine-treated groups and the barnidipine and methylprednisolone groups in terms of MDA levels $(p>0.008)$.
\end{abstract}

CONCLUSION: A single dose of barnidipine $(10 \mathrm{mg} / \mathrm{kg})$ and methylprednisolone are not effective and not sufficient to prevent spinal ischemia-reperfusion injury in rats.

Keywords: Barnidipine; calcium channel blocker; methyl prednisolone; spinal cord injury.

Cite this article as: Daltaban IS, Misir S, Turksoy VA, Ak H, Cakir E. The effects of barnidipine on an experimental ischemia reperfusion model of spinal cord injury and comparison with methyl prednisolone. North Clin Istanb 2019;6(2):103-109.

Spinal cord injury (SCI) can be divided into primary and secondary mechanisms [1]. Increased intracellular calcium concentration plays an important role in the secondary mechanism of spinal cord injury (SSCI) [2]. Changes in the membrane permeability with respect to intracellular calcium play an important role in neuronal degeneration following an injury to the central nervous system, as has been reported by many studies [3]. Several mechanisms including vascular deterioration, increased blood-spinal barrier permeability, ionic dysregulation,

Received: December 26, 2018 Accepted: August 18, 2018 Online: October 09, 2018

Correspondence: Dr. Iskender Samet DALTABAN. Bozok Universitesi Tip Fakultesi, Norosirurji Anabilim Dali, Yozgat, Turkey.

Tel: +90 3542127060 - 3722 e-mail: isamet79@hotmail.com

(c) Copyright 2019 by Istanbul Provincial Directorate of Health - Available online at www.northclinist.com

(c) (1) (8) 
edema, excessive intracellular calcium concentration, glutamate excitotoxicity, lipid peroxidation, an autoreactive inflammatory reaction, and apoptosis are involved in the second phase of SCI [4]. Increased intracellular calcium activates endonucleases and proteases. It also causes apoptosis, necrosis, acidosis, and mitochondrial damage. As a result, free radicals get increased and eventually cause axonal damage. Blockage of voltage-dependent calcium channels enhances the preservation of axonal conduction following traumatic injury [3].

Calcium channel blockers have been shown to increase blood flow in the spinal cord after trauma in many studies [5-9]. They regulate microvascularity, selectively inhibit peripheral vasodilatation by acting on central nervous system veins and prevent ischemic deficits. In this manner, they increase the perfusion of neural tissues. Improved axonal perfusion was shown by measuring induced motor and somatosensory potentials [10].

Methylprednisolone is a glucocorticoid and its possible healing effects in SCI have been a subject of much research for years. Different results have been reported from different studies [11-13]. The mechanisms of action of methylprednisolone in SCI include facilitation of neuronal excitability and impulse conduction, improved blood flow, and preservation of cord ultrastructure through a reduction of injury-induced, free radicalcatalyzed lipid peroxidation [14]. These reactions are primarily involved in the secondary mechanism of the SCI. In NASCIS II (National Acute Spinal Cord Injury Study) and NASCIS III studies, a dose of $30 \mathrm{mg} / \mathrm{kg}$ intravenous methylprednisolone bolus was given [13].

Barnidipine is a dihydropyridine derivative with high affinity for L-type calcium channels in a lipophilic character. In the presenting experimental study, we aimed to evaluate the presence of any healing effect of barnidipine, which has never before been studied with respect to SCI and to compare its effects with methylprednisolone.

\section{MATERIAL AND METHOD}

The local ethics committee of Laboratory Animals approved the study (date: 21.01.20014, number: 2014/2). A total of 32 Spraque Dawley albino adult female rats weighing $250 \pm 30$ grams were divided into 4 groups ( $n=8$, for each group). All animals were weighed before operation and sacrifice. They were kept in a light-controlled room with a 12:12-hour light-dark cycle; a tem- perature of $22 \pm 0.5^{\circ} \mathrm{C}$, and relative humidity of $65 \%$ $70 \%$, all of which were kept constant. Animals received a standard rat diet along with water and libitum. None of them had any neurological disorders before the operation and they had not been used in another study. For the anesthesia of animals, $8 \mathrm{mg} / 100 \mathrm{~g}$ ketamin (Alfamine \%10, Ege Vet Hayvanc1lı San. Ve Tic. Ltd. Şti., İzmir/ Turkey) and $1 \mathrm{mg} / 100 \mathrm{~g}$ xylazin (Alfazyne \%2, Ege Vet Hayvancilık San. Ve Tic. Ltd. Şti., İzmir/Turkey) were used intraperitoneally.

\section{Surgical Procedure}

The rats were shaved from the abdomen to the leg. The surgical area was painted with batticon, after which it was shaved and draped. After sterile surgical preparation, a midline laparotomy was made and the intestines were taken out by deflecting them to the right and covering them with warm and wet compresses to decrease the loss of heat and fluid. After the retroperitoneal area was opened, the abdominal aorta and inferior vena cava were identified and isolated. Spinal cord ischemia was created by clamping the aorta just below the renal vein with a medium-pressured aneurysm clip for 30 minutes as observed in previous studies (Yaşargil aneurysm clip, Aesculap) $[15,16]$.

\section{Groups}

Group 1 (sham-operated group, $\mathrm{n}=8$ ): In this group, abdominal aorta was revealed by laparotomy without performing clip application. About 24 hours after laparotomy, spinal cord tissue of thoracic vertebra (between T8 - T12) was removed.

Group 2 (only ischemia group, $n=6$ ): In this group, rats underwent laparotomy to reveal abdominal aorta and after that ischemia was generated by the clipping with the aid of medium-pressured aneurysm clip for 30 minutes. In this group, two rats died after surgical procedure and were excluded from the study. About 24 hours after the surgical procedure, thoracic vertebrae were removed.

Group 3 (Barnidipine-treated group, $n=8$ ). About 15 minutes after the above mentioned surgical procedures and after performing ischemia, barnidipine $(10 \mathrm{mg} / \mathrm{kg})$ (Libradin, Gürel İlaç, Turkey) was given intraperitoneal1y. Close to 24 hours after these procedures, the thoracic vertebrae were removed.

Group 4 (methylprednisolone-treated group; $n=6$ ): 
About 15 minutes after performing laparotomy and ischemia, methylprednisolone $(30 \mathrm{mg} / \mathrm{kg}$ ) (Prednol, Mustafa Nevzat İlaç, Turkey) was given. Close to 24 hours after these procedures, thoracic vertebrae were removed. In this group, 2 rats died just after surgical procedure and were excluded from the study.

\section{Motor Examination}

All animals were assessed according to the motor examination score defined by Tarlov and Klinger 1 hour after before surgical procedure and before being sacrificed [17].

The criterion used to study the motor function of the feet posterior was the following:

0 - no volunteer movement

1 - perceptive movement in articulations

2 - good articular movements but inability to get up

3 - the ability to get up and walk

4 - complete recovery

\section{Histopathological Evaluation}

Histopathological evaluation was performed under light microscopy at magnifications of 100 and 400 (Olympus BX51, DP71). Samples were prepared from spinal cord pieces about $5 \mathrm{~mm}$ thick. Prepared specimens were passed through alcohol, xylose and formaldehyde solutions and embedded in paraffin blocks. Tissue specimens were then cut with the help of a microtome to a thickness of 5 microns. The tissue specimens were then subjected to deparaffinization with xylene three times under a temperature of $60^{\circ} \mathrm{C}$. The samples were washed with water after rehydration with the aid of alcohol. After that, they were stained with hematoxylineosin stain.

\section{Analysis of Tissue Malondialdehyde (MDA) Level}

MDA levels in tissue samples were determined using the method developed by Mihara and Uchiyama [18].

\section{Sample Preparation}

The tissues were weighed and homogenized in an icecold $1.15 \% \mathrm{KCl}$ solution containing $0.50 \mathrm{ml}$ Triton X-100 (10\% weight/volume) by using an Ultra Turrax T25 homogenizer (Jane \& Kunkel, Germany). The homogenate was centrifuged at $9,500 \mathrm{rpm}$ for $4 \times 10$ seconds at $4^{\circ} \mathrm{C}$, and the supernatant was used for the determination of MDA levels in tissue samples.
Sample Analysis

1. $500 \mu \mathrm{l}$ of homogenate was mixed with $3 \mathrm{ml}$ of $1 \%$ $\mathrm{H} 3 \mathrm{PO} 4$.

2. The mixture was transferred to a test tube containing $1 \mathrm{ml}$ of thiobarbituric acid (TBA) solution $(0.672 \%$, $\mathrm{w} / \mathrm{v}$ ) and then was incubated in a boiling water bath for $45 \mathrm{~min}$.

3. The tubes were centrifuged at $1000 \times \mathrm{g}$ for $10 \mathrm{~min}$ in the room temperature.

4. The absorbance of the organic phase was observed at $532 \mathrm{~nm}$ wavelength.

$1 \mathrm{mmol}$ of 1,1,3,3-tetramethoxypropane in $100 \mathrm{ml}$ of $0.01 \mathrm{M} \mathrm{HCl}$ was incubated in $50^{\circ} \mathrm{C}$ for 1 hour, and the resulting hydrolysis of the compound MDA at 40, $20,10,5,2.5,1.25,0.625$ and $0.312 \mathrm{nmol} / \mathrm{mL}$ working standards were prepared. The results acquired with the standard graph were drawn. By using this graph, levels of tissue MDA were calculated as nmol MDA/g wet tissue.

\section{Statistical Analysis}

In the analysis and comparison of malondialdehyde (MDA) levels and motor examination between groups, the Kruskal-Wallis Variance analysis test was used because the number of animals in the groups was under 10. Mann-Whitney $U$ test was used in order to determine which groups are different. Bonferroni correction was performed during the use of this test. Although the significance level of the Mann-Whitney $U$ test is 0.05 , it was divided by 6 (the number of comparisons), and the significance value was accepted as $\mathrm{p}<0.008$. Values lower than $<0.008$ were considered significant.

\section{RESULTS}

Our study consisted of 4 groups consisting of 8 rats in the sham-operated group, 6 rats in only ischemia group, 8 rats in the barnidipine-treated group, and 6 rats in the methylprednisolone-treated group.

\section{Motor Examination}

Results of motor examination according to Tarlov rating scale in groups are presented in Table 1. According to the Kruskal-Wallis test, a significant correlation was detected on the $1^{\text {st }}$ and $24^{\text {th }}$-hour examination $(p<0.008)$. To compare the difference between subgroups, the Mann-Whitney U test was performed. A 
TABLE 1. Results of motor examination according to Tarlov rating scale in groups

\begin{tabular}{lcc|lcc} 
Groups & $1^{\text {st }} \mathrm{h}$. & $24^{\text {th }} \mathrm{h}$. & Groups & $1^{\text {st }} \mathrm{h}$. & $24^{\text {th }} \mathrm{h}$. \\
\hline K1 & 4 & 4 & B1 & 3 & 3 \\
K2 & 4 & 4 & B2 & 3 & 4 \\
K3 & 4 & 4 & B3 & 2 & 2 \\
K4 & 4 & 4 & B4 & 3 & 3 \\
K5 & 4 & 4 & B5 & 2 & 3 \\
K6 & 4 & 4 & B6 & 3 & 3 \\
K7 & 4 & 4 & B7 & 3 & 4 \\
K8 & 4 & 4 & B8 & 2 & 2 \\
I1 & 2 & 2 & P1 & 2 & 3 \\
I2 & 2 & 2 & P2 & 3 & 3 \\
I3 & 3 & 2 & P3 & 3 & 4 \\
I4 & 3 & 3 & P4 & 3 & 3 \\
I5 & 2 & 2 & P5 & 3 & 4 \\
I6 & 2 & 3 & P6 & 2 & 2 \\
\hline
\end{tabular}

K: Sham-operated group; I: Only-iskemiea group; B: Barnidipine-treated group; $\mathrm{P}$ : Methyle prednisolone treated group; h: Hour

significant correlation was detected between sham-operated and methylprednisolone-treated groups at the first hour $(p<0.008)$. However, no significant difference was observed at the $24^{\text {th }}$ hour $(p>0.008)$. There was a significant correlation between the sham-operated group and barnidipine- treated groups and sham-operated and only ischemia groups at the $1^{\text {st }}$ and $24^{\text {th }}$ hour in terms of motor examination $(\mathrm{p}<0.008)$. However, there was no significant difference between only ischemia and barnidipine-treated groups and only ischemia and methylprednisolone-treated groups $(p>0.008)$. Also, there was no significant difference between barnidipine-treated and methylprednisolone-treated groups.

\section{Histopathological Results}

In group 1 (control group); light microscopic examination of the sham-operated group revealed findings consistent with normal spinal cord structure (Fig. 1A). Light microscopic examination of only ischemia group, barnidipine-treated, and methylprednisolone-treated groups were similar to the sham-operated group except for polymorphonuclear leukocyte infiltration and a small amount of axonal swelling (Fig. 1 B-D, respectively). When compared to the barnidipine-treated group, morphological changes were similar or more intense in the methylprednisolone-treated group.

\section{Results of Malondialdehyde Levels}

MDA values are presented in Figure 2. Mean MDA level was 277.22 (range: 185.58-428.80). The Kruskal-Wallis test pointed out a significant correlation in terms of MDA levels. To compare the difference between groups, the Mann-Whitney $U$ test was performed. There was a significant correlation between the sham-operated group and methylprednisolone-treated groups in terms of MDA level $(p<0.008)$. However, there was no significant correlation between shamoperated and only ischemia groups and only ischemia and barnidipine- treated groups ( $p>0.008)$. A significant correlation was found between only ischemia and methylprednisolone-treated groups $(p<0.008)$. However, no significant correlation was detected between barnidipine-treated and methylprednisolone-treated groups $(\mathrm{p}>0.008)$.
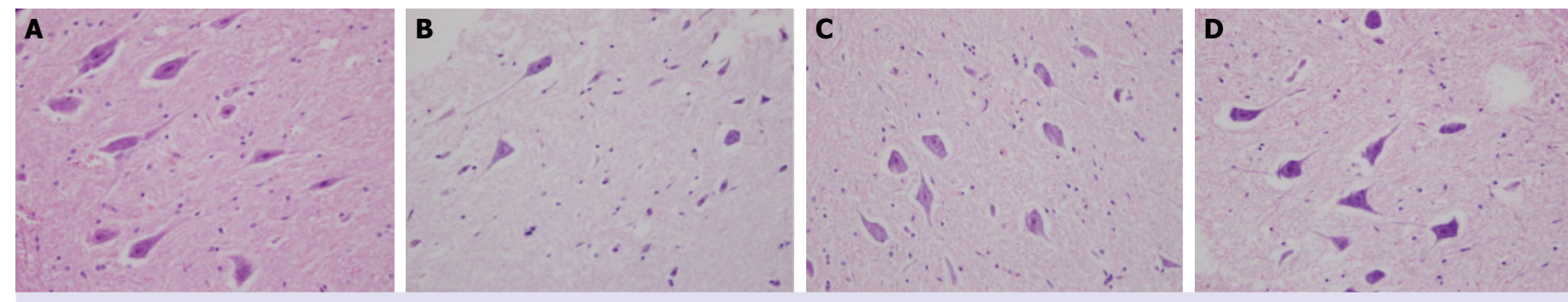

FIGURE 1. (A) Light microscopic examination of control group revealing findings consistent with normal spinal cord structure. (B) Light microscopic examination of ischemia group revealing findings similar to control group except for polymorphonuclear leucocyte infiltration and small amount of axonal swelling. (C) Light microscopic examination of barnidipine-treated group revealing findings similar to control group except for polymorphonuclear leucocyte infiltration and small amount of axonal swelling. (D) Light microscopic examination of methylprednisolone-treated group revealing findings similar to control group except for polymorphonuclear leucocyte infiltration and small amount of axonal swelling. 


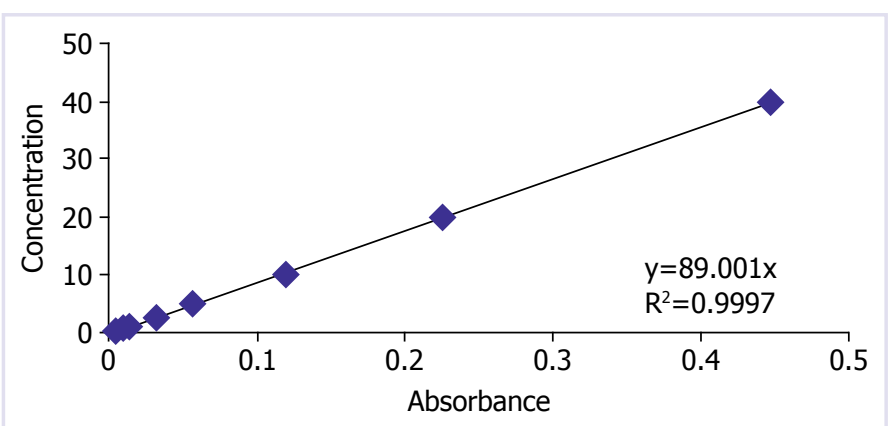

FIGURE2. MDA values.

\section{DISCUSSION}

Spinal cord injury (SCI) remains one of the main causes of disability [19]. The primary morphological changes include disruption of tissue integrity, damage to blood vessels and axons, edema, and deterioration of cells. Secondary injuries occurring during the hours and days following a primary injury include some pathophysiological changes such as ischemia, ion infiltration, production of oxygen free radicals, and lipid peroxidation [20].

In animal models, specific therapeutic methods have been applied to alleviate spinal cord injuries. However, to date, these promising results have failed to manifest at the bedside (beyond the laboratory) [21,22]. A spinal injury can be predicted in some clinical situations, such as in the surgical treatment of intraspinal tumors [23]. An acute injury of the spinal cord initiates a series of vascular, biochemical, and inflammatory events resulting in the development of secondary tissue damage. Experimental studies and clinical trials in humans have shown that the extent of this secondary tissue damage can be limited by pharmacologic intervention at appropriate intervals after injury [24]. Thus, the results of our study indicated that barnidipine and methylprednisolone have no preventive effect on SCI on ischemia-reperfusion model at a dose of $10 \mathrm{mg} / \mathrm{kg}$ and $30 \mathrm{mg} / \mathrm{kg}$, respectively. Also, barnidipine has no therapeutic advantage over methylprednisolone.

Many studies have emphasized the importance of ischemia in the secondary injury of the spinal cord. Some researchers have used a variety of drugs, including dopamine, adrenaline, nimodipine, dextran, and blood transfusions to improve spinal cord blood flow after spinal trauma and have shown that these methods improve axonal function $[25,26]$. To further confirm these encouraging results that show improvement in spinal cord post-traumatic ischemia, researches continue to test the combinations of these drugs [8]. For the same purpose, high-dose steroid treatments are commonly used in the prevention of secondary injury [27]. Methylprednisolone has been shown to have beneficial effects on SCI due to its neuroprotective effect and inhibition of lipid peroxidation [28].

It is known that calcium channel blockers have positive effects on microcirculation and spinal perfusion after SCI. Calcium channel blockers have been shown to increase blood flow in the spinal cord after trauma in many studies $[5,6]$. They selectively inhibit peripheral vasodilatation by acting on CNS veins and prevent ischemic deficits. Further, they increase perfusion in neural tissues. Therefore, it has been shown that increased perfusion improved the axonal perfusion by measuring induced motor and somatosensory potentials [10]. Calcium channel blockers also have a vasoprotective effect.

Barnidipine, a dihydropyridine derivative, is more effective on the peripheral vascular structure. It is a type A calcium channel blocker [29] that meets these challenges of modern pharmacotherapy. The advantages of once a day dosage, good tolerability, and strong antihypertensive effects contribute to excellent patient adherence and make a valuable contribution to the hypertension treatment plan [30]. With respect to the antihypertensive effect of barnidipine, $10 \mathrm{mg}$ once daily has not been found to be significantly different from amlodipine $5-10 \mathrm{mg}$ once daily [31]. Although the effects of calcium channel blockers on the secondary mechanism of acute SCI are well-known, the possible healing effects of barnidipine (a type A calcium channel blocker), have not been studied in the literature before. In our study, we tried to pave the way for future researchers who may wish to study the therapeutic effects of barnidipine on SCI.

Since there is no curative treatment for SCI, it is important to form an ideal animal model, identify the mechanisms of injury, and develop a therapy for individuals exposed to SCI [32]. None of the SCI models are perfect because the spinal cord ischemic models differ from the human ischemia table in some aspects. One of the most important reasons for this is that spinal cord feeding differs among all living species, even between species in the same genus. In our study, abdominal aortic clamping method was used from the left renal artery as per the method described by Zivin et al. which is reliable, easy and cheap to perform [33]. The neurological deficits were obtained at various grades which were consistent with the literature. A change in locomotor response was observed in the other groups except for the sham-op- 
erated group, which proved that our work was planned correctly. Locomotor responses in case an animal died of exploration/anxiety have been shown to represent a predictive factor for the addictive properties of a drug or an animal vulnerable to the drug.

In the histopathological evaluation of the tissue samples, the findings of the sham-operated group were compatible with the normal spinal cord structure. Polymorphonuclear leukocyte infiltration and mild axonal swelling were observed in all other groups, however, this appearance did not show any significant difference or superiority among the groups. On the other hand, the fact that barnidipine-treated group had the same histopathological appearance of the only ischemia group suggests that barnidipine did not display any neuroprotective activity after the spinal ischemia-reperfusion injury.

When the motor examination scores at the $1^{\text {st }}$ and $24^{\text {th }}$ hours were compared, there was a statistically significant difference between the sham-operated group and the other groups, and it was accepted as a sign that sufficient neurological deficits were formed in all groups. No statistically significant difference was found between the groups except the sham-operated group.

Malondialdehyde (MDA) is an end-product of lipid peroxidation. Its serum levels are mostly used in spinal cord injury studies $[34,35]$. In our study, according to the statistics of MDA values measured in order to evaluate the biochemical changes, the statistical evaluation between the sham-operated and methylprednisolonetreated group and between the only ischemia and the methylprednisolone-treated group was found significant. Statistically, this difference was not significant, although different results were obtained between the group receiving barnidipine and the sham-operated group. Similarly, although there was a minor difference between these groups, barnidipine-treated and methyl-prednisolonetreated groups were statistically insignificant. Despite the decrease in MDA levels in subjects who received barnidipine, this decrease was not statistically signifcant. However, in the subjects who received methylprednisolone, the tissue was statistically significant when compared with MDA change, sham-operated and only ischemia groups. These changes in MDA value were interpreted as a beneficial effect of methylprednisolone in spinal cord ischemia-reperfusion injury. Several studies have demonstrated that methylprednisolone contributes to the recovery of the spinal cord, which facilitated the prevention of lipid peroxidation and increased vascular permeability in damaged tissue [36-38]. In previous works, methylprednisolone has been shown to reduce MDA levels consistent with this study. The decrease in MDA levels in the subjects treated with barnidipine was found to be statistically insignificant.

In our study, the duration was limited to 24 hours and barnidipine was given as $10 \mathrm{mg} / \mathrm{kg}$ on a single dose only on the first day. The difference between the groups given and not given barnidipine was observed but it was not found statistically significant. If the waiting period was kept longer on the day after the drug was administered and barnidipine was administered at repeated doses, perhaps significant results could be obtained. The results suggest that, at least in an animal model, the spinal cord may develop a new approach to the treatment of the ischemic injury.

\section{Conclusion}

A single dose of barnidipine $(10 \mathrm{mg} / \mathrm{kg})$ and methylprednisolone $(30 \mathrm{mg} / \mathrm{kg})$ dose is not effective and not sufficient to prevent spinal ischemia-reperfusion injury in rats.

Conflict of Interest: There is no conflict of interests.

Financial Disclosure: The authors declared that this study has received no financial support.

Authorship Contributions: Concept - ISD; Design - ISD; Supervision - ISD; Materials - SM; Data collection and/or processing - HA; Analysis and/or interpretation - VAT; Writing - ISD; Critical review - EC.

\section{REFERENCES}

1. Anwar MA, Al Shehabi TS, Eid AH. Inflammogenesis of Secondary Spinal Cord Injury. Front Cell Neurosci 2016;10:98. [CrossRef]

2. Oyinbo CA. Secondary injury mechanisms in traumatic spinal cord injury: a nugget of this multiply cascade. Acta Neurobiol Exp (Wars) 2011;71:281-99.

3. Agrawal SK, Nashmi R, Fehlings MG. Role of L- and N-type calcium channels in the pathophysiology of traumatic spinal cord white matter injury. Neuroscience 2000;99:179-88. [CrossRef]

4. Garcia E, Aguilar-Cevallos J, Silva-Garcia R, Ibarra A. Cytokine and Growth Factor Activation In Vivo and In Vitro afterSpinal Cord Injury. Mediators Inflamm 2016;2016:9476020. [CrossRef]

5. Fehlings $\mathrm{MG}$, Tator $\mathrm{CH}$, Linden RD. The effect of nimodipine and dextran on axonal function and blood flow following experimental spinal cord injury. J Neurosurg 1989;71:403-16. [CrossRef]

6. Imamura $\mathrm{H}$, Tator $\mathrm{CH}$. Effect of intrathecal nimodipine on spinal cord blood flow and evoked potentials in the normal or injured cord. Spinal Cord 1998;36:497-506. [CrossRef]

7. Ceylan S, Ilbay K, Baykal S, Ceylan S, Sener U, Ozmenoğlu M, et al. Treatment of acute spinal cord injuries: comparison of thyrotropin-releasing hormone and nimodipine. Res Exp Med (Berl) 1992;192:23- 


\section{3. [CrossRef]}

8. Guha A, Tator CH, Piper I. Effect of a calcium channel blocker on posttraumatic spinal cord blood flow. J Neurosurg 1987;66:423-30. [CrossRef]

9. Ross IB, Tator CH. Spinal cord blood flow and evoked potential responses after treatment with nimodipine or methylprednisolone in spinal cord-injured rats. Neurosurgery 1993;33:470-6. [CrossRef]

10. Amar AP, Levy ML. Pathogenesis and pharmacological strategies for mitigatingsecondary damage in acute spinal cord injury. Neurosurgery 1999;44:1027-39. [CrossRef]

11. Bowers CA, Kundu B, Hawryluk GW. Methylprednisolone for acute spinal cord injury: an increasingly philosophical debate. Neural Regen Res 2016;11:882-5. [CrossRef]

12. Hugenholtz H, Cass DE, Dvorak MF, Fewer DH, Fox RJ, Izukawa $\mathrm{DM}$, et al. High-dose methylprednisolone for acute closed spinal cord injury--only a treatment option. Can J Neurol Sci 2002;29:227-35.

13. Cheung V, Hoshide R, Bansal V, Kasper E, Chen CC. Methylprednisolone in the management of spinal cord injuries: Lessons from randomized, controlled trials. Surg Neurol Int 2015;6:142. [CrossRef]

14. Hall ED, Braughler JM. Glucocorticoid mechanisms in acute spinal cord injury: a review and therapeutic rationale. Surg Neurol 1982;18:320-7.

15. Carrillo SE, Guimarães SB, Vasconcelos PR, Vasconcelos PR. Is subdiaphragmatic aortic cross-clamping a suitable model for spinal cord ischemia/reperfusion injury study in rats? Acta Cir Bras 2006;21:21922. [CrossRef]

16. Kerman M, Şenol N, Özgüner M. Effect of melatonin on spinal cord injury induced lipid peroxidation in rats: prognostic value of malondialdehyde. SDU The Journal of Health Science 2011;2:65-9.

17. Tarlov IM. Spinal cord compression studies. III. Time limits for recovery after gradual compression in dogs. AMA Arch Neurol Psychiatry 1954;71:588-97. [CrossRef]

18. Mihara M, Uchiyama M. Determination of malonaldehyde precursor in tissues by thiobarbituric acid test. Anal Biochem 1978;86:271-8.

19. Singh A, Tetreault L, Kalsi-Ryan S, Nouri A, Fehlings MG. Global prevalence and incidence of traumatic spinal cord injury. Clin Epidemiol 2014;6:309-31. [CrossRef]

20. Lou J, Lenke LG, Ludwig FJ, O’Brien MF. Apoptosis as a mechanism of neuronal cell death following acute experimental spinal cord injury. Spinal Cord 1998;36:683-90. [CrossRef]

21. Martirosyan NL, Feuerstein JS, Theodore N, Cavalcanti DD, Spetzler RF, Preul MC. Blood supply and vascular reactivity of the spinal cord under normal and pathological conditions. J Neurosurg Spine 2011;15:238-51. [CrossRef]

22. Varma AK, Das A, Wallace G 4th, Barry J, Vertegel AA, Ray SK, et al. Spinal cord injury: a review of current therapy, future treatments, and basic science frontiers. Neurochem Res 2013;38:895-905. [CrossRef]
23. Marcon RM, Barros Filho TEPD, Oliveira RP, Cristante AF, Taricco MA, Colares G, et al. Experimental study on the action of methylprednisolone on Wistar rats before spinal cord injury. Acta Ortop Bras 2010;18:26-30. [CrossRef]

24. Olby N. Current concepts in the management of acute spinal cord injury. J Vet Intern Med 1999;13:399-407. [CrossRef]

25. Tator $\mathrm{CH}$, Fehlings MG. Review of the secondary injury theory of acute spinal cord trauma with emphasis on vascular mechanisms. J Neurosurg 1991;75:15-26. [CrossRef]

26. Kwon BK, Oxland TR, TetzlaffW. Animal models used in spinal cord regeneration research. Spine (Phila Pa 1976) 2002;27:1504-10. [CrossRef]

27. Topsakal C, Erol FS, Ozveren MF, Yilmaz N, Ilhan N. Effects of methylprednisolone and dextromethorphan on lipid peroxidation in an experimental model of spinal cord injury. Neurosurg Rev 2002;25:258-66.

28. Hall ED. Antioxidant therapies for acute spinal cord injury. Neurotherapeutics 2011;8:152-67. [CrossRef]

29. Braunwald E. Mechanism of action of calcium-channel-blocking agents. N Engl J Med 1982;307:1618-27. [CrossRef]

30. Liau CS. Barnidipine: a new calcium channel blocker for hypertension treatment. Expert Rev Cardiovasc Ther 2005;3:207-13. [CrossRef]

31. Rossetti G, Pizzocri S, Brasca F, Pozzi M, Beltrami LM, Bolla GB, et al. Antihypertensive effect of barnidipine $10 \mathrm{mg}$ or amlodipine 5 to $10 \mathrm{mg}$ once daily in treatment-naive patients with essential hypertension: A 24-week, randomized, open-label, pilot study. Curr Ther Res Clin Exp 2008;69:192-206. [CrossRef]

32. Zhang N, Fang M, Chen H, Gou F, Ding M. Evaluation of spinal cord injury animal models. Neural Regen Res 2014;9:2008-12.

33. Zivin JA, Doppman JL, Reid JL, Tappaz ML, Saavedra JM, Kopin IJ, et al. Biochemical and histochemical studies of biogenic amines in spinal cord trauma. Neurology 1976;26:99-107. [CrossRef]

34. Christie SD, Comeau B, Myers T, Sadi D, Purdy M, Mendez I. Duration of lipid peroxidation after acute spinal cord injury in rats and the effect of methylprednisolone. Neurosurg Focus 2008;25(5):E5.

35. Sahin Kavakl1 H, Koca C, Alıc1 O. Antioxidant effects of curcumin in spinal cord injury in rats. Ulus Travma Acil Cerrahi Derg 2011;17:148. [CrossRef]

36. Taoka Y, Okajima K, Murakami K, Johno M, Naruo M. Role of neutrophil elastase in compression-induced spinal cord injury in rats. Brain Res 1998;799:264-9. [CrossRef]

37. Cavus G, Altas M, Aras M, Ozgür T, Serarslan Y, Yilmaz N, et al. Effects of montelukast and methylprednisolone on experimental spinal cord injury in rats. Eur Rev Med Pharmacol Sci 2014;18:1770-7.

38. Kanter M, Coskun O, Kalayci M, Buyukbas S, Cagavi F. Neuroprotective effects of Nigella sativa on experimental spinal cord injury in rats. Hum Exp Toxicol 2006;25:127-33. [CrossRef] 